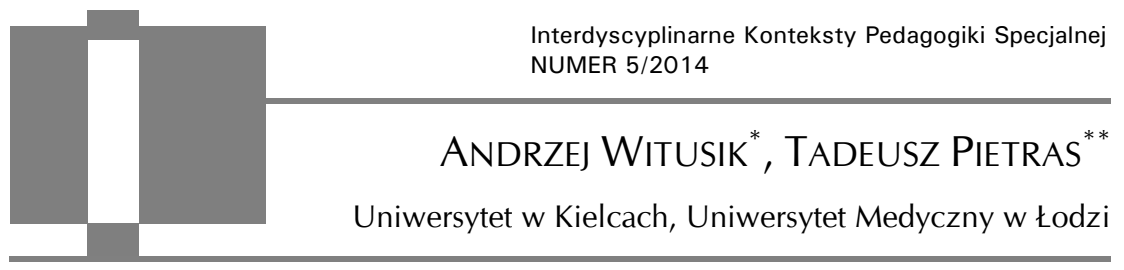

\title{
Nauczanie i wychowanie w pracy z pacjentami chorymi na schizofrenię
}

\begin{abstract}
Witusik Andrzej, Pietras Tadeusz, Teaching and education in work with patients with schizophrenia [Nauczanie i wychowanie w pracy z pacjentami chorymi na schizofrenię]. Interdyscyplinarne Konteksty Pedagogiki Specjalnej, nr 5, Poznań 2014. Pp. 41-50. Adam Mickiewicz University Press. ISBN 978-83-232-2866-0. ISSN 2300-391X.

The purpose of this paper is to discuss the role of pedagogical work in the rehabilitation of patients with schizophrenia. The article discusses ways of rehabilitation of patients with schizophrenia taking into account the importance of teachers work. This model developed G. Thornicroft and coworkers and it is called the matrix model.
\end{abstract}

KEY WORDS: psychiatric rehabilitation, social psychiatry, matrix model.

Wstęp

Schizofrenia jest ciężkim zaburzeniem psychicznym, na które choruje ok. $1 \%$ populacji ${ }^{1}$. Choroba ta zaczyna się $\mathrm{w}$ młodym wieku

* Z Pracowni Psychologii Instytutu Nauk Pedagogicznych Wydziału Nauk Społecznych Filii w Piotrkowie Trybunalskim Uniwersytetu Jana Kochanowskiego w Kielcach.

** Z I Katedry Chorób Wewnętrznych Uniwersytetu Medycznego w Łodzi.

${ }^{1} \mathrm{~K}$. Kasai, Toward an interdisciplinary science of adolescence: insights from schizophrenia research, „Neuroscience Research”, 2013 Feb, 75(2), s. 89-93, doi: 10.1016/ j.neures.2012.12.001. 
i trwa do późnej starości. Rozwija się wskutek interakcji czynników: genetycznych, uszkadzających wewnątrzmaciczny rozwój płodu, okołoporodowych i w efekcie nieprawidłowej stymulacji środowiskowej we wczesnym okresie życia dziecka². Tylko $10 \%$ chorych na schizofrenię wraca do aktywności przedchorobowej w stopniu umożliwiającym pracę zawodową ${ }^{3}$. Około $10 \%$ chorych popełnia samobójstwo.

Praca psychoedukacyjna i pedagogiczna z chorymi na schizofrenię stanowi jedną $\mathrm{z}$ podstawowych strategii terapeutycznych stosowanych w leczeniu tej choroby (obok farmakoterapii za pomocą leków przeciwpsychotycznych - neuroleptyków $)^{4}$.

Powstaje pytanie o miejsce zawodu pedagoga specjalnego w pracy z osobami chorymi na schizofrenię. Celem artykułu jest analiza znaczenia przygotowania pedagogicznego $\mathrm{w}$ pracy $\mathrm{z}$ osobami chorymi na zaburzenia psychotyczne, a pośrednio także wskazanie konieczności rzetelnego kształcenia pedagogów specjalnych z podstaw psychiatrii.

\section{Rehabilitacja psychiatryczna chorych na schizofrenię}

Wsparcie niefarmakologiczne chorych na schizofrenię stanowi ważny element terapii. Może się ono odbywać na poziomie:

- rehabilitacji psychiatrycznej, rozumianej jako korekta powstałych zaburzeń funkcjonowania społecznego u pojedynczego pacjenta ${ }^{5}$

2 J. Wciórka, Psychozy schizofreniczne, [w:] Psychiatria, t. II: Psychiatria kliniczna, red. J. Rybakowski, S. Pużyński, J. Wciórka, Wydawnictwo Medyczne Urban \& Partner, Wrocław 2011, s. 195-269.

3 S. Marwaha, S. Johnson, Schizophrenia and employment - a review, "Social Psychiatry and Psychiatric Epidemiology", 2004 May, 39(5), s. 337-349.

${ }^{4}$ A.B. Murray-Swank, L. Dixon, Family psychoeducation as an evidence-based practice, „CNS Spectrums”, 2004 Dec, 9(12), s. 905-912.

5 T.K. Rajji, D. Miranda, B.H. Mulsant, Cognition, function, and disability in patients with schizophrenia: a review of longitudinal studies, "Canadian Journal of Psychiatry", 2014 Jan, 59(1), s. 7-13. 
- psychiatrii środowiskowej (społecznej), oznaczającej takie oddziaływanie na środowisko społeczne chorego, które umożliwia skuteczną readaptację chorych psychicznie do życia w społeczeństwié.

Rehabilitacja psychiatryczna odbywa się na poziomie kompensowania u pacjenta deficytów poznawczych i behawioralnych powstałych w wyniku procesu psychotycznego ${ }^{7}$. Model rehabilitacji jest bliski w swoim założeniu traktowaniu każdego zaburzenia, w tym schizofrenii, jako zespołu deficytów. Leczenie i rehabilitacja polegają na skompensowaniu tych deficytów za pomocą różnych metod korekcji, w tym także na drodze procesów wychowawczych oraz edukacyjnych. Model ten stanowi podstawę teoretyczną różnych metod kompensowania zaburzenia o wykazanej naukowo skuteczności, także tych przynależących tradycyjnie do obszaru pedagogiki specjalnej. U jego podstaw leży myślenie patogenetyczne, typowe dla tradycyjnej medycyny naprawczej, która powstała w XIX w. wraz z rozwojem nauk empirycznych i linearnego myślenia kartezjańskiego.

Model ten jest krytykowany ze względu na traktowanie wszelkich zaburzeń w kategorii deficytu, braku, niedoboru, gorszej jakości. Zwraca się uwagę na „defektologiczny charakter” omawianego paradygmatu. Współczesne psychiatria i pedagogika specjalna odeszły od modelu deficytu - skłaniają się raczej do modelu uczestnictwa społecznego osób odmiennych, w tym także chorych na schizofrenię 8 . Model ten oznacza docelowo stworzenie możliwości

${ }^{6}$ S. Yamaguchi, S.I. Wu, M. Biswas, M. Yate, Y. Aoki, E.A. Barley, G. Thornicroft, Effects of short-term interventions to reduce mental health-related stigma in university or college students: a systematic review, "The Journal of Nervous and Mental Disease", 2013 Jun, 201(6), s. 490-503, doi: 10.1097/NMD.0b013e31829480df.

7 A. Bose, S.M. Agarwal, S.V. Kalmady, G. Venkatasubramanian, Cognitive Mapping Deficits in Schizophrenia: A Critical Overview, „Indian Journal Psychological Medicine", 2014 Jan, 36(1), s. 9-26.

8 A. Krause, Wspótczesne paradygmaty pedagogiki specjalnej, Oficyna Wydawnicza Impuls, Kraków 2010; O. Speck, Niepetnosprawni w społeczeństwie. Podstawy ortopedagogiki, Gdańskie Wydawnictwo Psychologiczne, Gdańsk 2005. 
udziału w życiu społecznym osób z różnymi zaburzeniami i ograniczeniami.

Metodami pracy $\mathrm{z}$ pacjentem nieprzystosowanym do życia w społeczeństwie z powodu deficytów wywołanych chorobą są:

- psychoedukacja, polegająca na nauczeniu pacjenta sposobów radzenia sobie z chorobą, przyjmowania właściwych dawek leków, rozpoznawania wczesnych objawów nawrotu choroby 9

- psychoterapia poznawczo-behawioralna, oznaczająca zmianę schematów poznawczych i przekonań kluczowych u pacjenta ${ }^{10}$

- pomoc socjalna11

- terapia systemowa rodziny pacjenta ${ }^{12}$

- terapia zajęciowa, biblioterapia, hortikuloterapia, muzykoterapia, choreoterapia, dogoterapia, hipoterapia itd.; metody te zostały szczegółowo opisane w monografii S. Leszto i in. ${ }^{13}$

Wiele z powyżej opisanych metod stanowi kompetencje społeczne pedagoga specjalnego. Warto zastanowić się nad tym, czy w zakresie studiów z dziedziny pedagogiki specjalnej nie wprowadzić specjalności, której przedmiotem byłoby postępowanie z oso-

${ }^{9}$ J. Sin, I. Norman, Psychoeducational interventions for family members of people with schizophrenia: a mixed-method systematic review, „The Journal of Clinical Psychiatry", 2013 Dec, 74(12), s. 1145-1162, doi: 10.4088/JCP.12r08308; W.T. Chien, S.F. Leung, F.K. Yeung, W.K. Wong, Current approaches to treatments for schizophrenia spectrum disorders, part II: psychosocial interventions and patient-focused perspectives in psychiatric care, "Neuropsychiatric Disease and Treatment”, 2013, 9, s. 1463-1481.

${ }^{10} \mathrm{G}$. Newton-Howes, R. Wood, Cognitive behavioural therapy and the psychopathology of schizophrenia: systematic review and meta-analysis, „Psychology and Psychotherapy: Theory, Research and Practice”, 2013 Jun, 86(2), s. 127-138, doi: 10.1111/j.2044-8341.2011.02048.

${ }^{11}$ K.T. Mueser, F. Deavers, D.L. Penn, J.E. Cassisi, Psychosocial treatments for schizophrenia, "Annual Review of Clinical Psychology”, 2013, 9, s. 465-497, doi: 10.1146/annurev-clinpsy-050212-185620.

12 M. Pakyurek, R. Yarnal, C. Carter, Treatment of psychosis in children and adolescents: a review, "Adolescent Medicine: State of the Art Reviews”, 2013 Aug, 24(2), s. $420-432$.

13 S. Leszto, A. Witusik, T. Pietras, Terapia pedagogiczna dorostych w psychiatrii i w medycynie somatycznej. Ujęcie psychologiczne, biomedyczne i aksjologiczne, Naukowe Wydawnictwo Piotrkowskie, Piotrków Trybunalski 2013. 
bami chorymi na schizofrenię. Propozycja ta jest o tyle interesująca, że część pedagogów specjalnych uzyskuje zatrudnienie w placówkach medycznych oraz placówkach pomocy społecznej zajmujących się osobami z zaburzeniami psychicznymi, o czym piszemy szczegółowo w następnym podrozdziale.

\section{Psychiatria środowiskowa wobec chorych na schizofrenię}

Celem psychiatrii środowiskowej jest wypracowanie takiego modelu opieki nad osobami z zaburzeniami psychicznymi, aby pacjenta „przywrócić" (w miarę możliwości) do funkcjonowania $\mathrm{w}$ środowisku lokalnym ${ }^{14}$. Cel ten stanowi priorytetowe zadanie nowocześnie rozumianej promocji zdrowia psychicznego ${ }^{15}$. Model ten zakłada leczenie, rehabilitację neuropsychologiczną, rehabilitację psychospołeczną i pomoc socjalną w środowisku lokalnym pacjenta, w warunkach najbardziej zbliżonych do naturalnego życia człowieka. Jest analogiczny do modelu probacji dotyczącego readaptacji społecznej osób mających konflikt z prawem, propagowanego przez A. Bałandynowicza ${ }^{16}$.

Według G. Thornicrofta, organizację i skuteczność metod oraz założeń psychiatrii środowiskowej można opisać trzema zmiennymi:

- wejścia, czyli zasobami środowiska społecznego (instytucje pracy socjalnej, lekarze psychiatrzy, pielęgniarki, sytuacja lokalowa)

- procesu, czyli strukturą organizacji opieki psychiatrycznej i rehabilitacji, zasobami ludzkimi, przygotowaniem merytorycznym pracowników, sposobami terapii oraz jej dostępnością

14 J. Wciórka, Terapia społeczna, [w:] Psychiatria, t. II: Podstawy psychiatrii, red. A. Bilikiewicz, J. Rybakowski, S. Pużyński, J. Wciórka, Wydawnictwo Medyczne Urban \& Partner, Wrocław 2002, s. 244-263.

15 G. Thornicroft, M. Tansella, W stronę lepszej psychiatrycznej opieki zdrowotnej, Instytut Psychiatrii i Neurologii, Warszawa 2010.

16 A. Bałandynowicz, Probacja. Resocjalizacja z udziałem społeczeństwa, Lex a Wolters Kluwer Polska, Warszawa 2011. 
- wyjścia, czyli skutecznością realizacji zamierzonych celów terapeutycznych.

Wszystkie te zmienne można rozpatrywać $\mathrm{w}$ aspekcie globalnym (systemu opieki zdrowia psychicznego $w$ danym państwie), lokalnym (w aspekcie społeczności) i indywidualnym (z punktu widzenia podmiotu $)^{17}$.

Model ten został nazwany przez swojego twórcę modelem macierzy (matrix model). Najpełniej oddaje on teoretyczne założenia idei psychiatrii środowiskowej. Wyznacza pewien cel, ma charakter normy powinnościowej, typowej dla nauk pedagogicznych rozumianych jako nauk o wychowaniu, nauczaniu i pożądanej zmianie człowieka według określonego paradygmatu ${ }^{18}$.

Opieka nad pacjentami w środowisku ma także ważny wymiar dydaktyczny dla społeczeństwa, w którym żyją osoby z zaburzeniami psychicznymi. Uczestnictwo chorych na schizofrenię w życiu społeczności lokalnej zmniejsza stygmatyzację i zwiększą stopień akceptacji obecności osób odmiennych psychicznie. Stygmatyzacja jest procesem niekorzystnym, nasilającym dysfunkcjonalność pacjentów ${ }^{19}$. Styczność społeczeństwa z osobami chorymi psychicznie uczestniczącymi w życiu codziennym społeczności lokalnej zmniejsza lęk przed zaburzeniami psychicznymi i obala powszechne negatywne stereotypy dotyczące obrazu chorego na schizofrenię $e^{20}$.

W polskiej pedagogice już dawno zwrócono uwagę na aspekty marginalizacji i stygmatyzacji osób z zaburzeniami psychicznymi21.

${ }_{17}$ M. Tansella, G. Thornicroft, H. Lempp, Lessons from community mental health to drive implementation in health care systems for people with long-term conditions, "International Journal of Environmental Research and Public Health", 2014 Apr, 30, 11(5), s. 4714-4728, doi: 10.3390/ijerph110504714.

${ }^{18}$ C. Wiśniewski, Filozofia a wychowanie, Naukowe Wydawnictwo Piotrkowskie, Piotrków Trybunalski 2002.

${ }^{19}$ P. Świtaj, Piętno choroby psychicznej, „Postępy Psychiatrii i Neurologii”, 2005, 14, s. 137-144.

${ }^{20}$ E. Goffman, Piętno. Rozważania o zranionej tożsamości, Gdańskie Wydawnictwo Psychologiczne, Gdańsk 2005.

${ }^{21}$ E. Trempała, Zagrożenia rozwoju człowieka marginalizacja i wykluczeniem w środowiskach lokalnych a pedagogika społeczna, [w:] Marginalizacja w problematyce pedagogi- 
W subiektywnym odczuciu autorów publikacji, procesami marginalizacji i stygmatyzacji chorych na schizofrenię $\mathrm{w}$ większym stopniu zajmowali się specjaliści z zakresu pedagogiki społecznej i pracy socjalnej niż pedagogiki specjalnej22. W akademickim podręczniku z zakresu pedagogiki specjalnej nie ma rozdziału poświęconego metodom pracy pedagogicznej oraz terapeutycznej z osobami dorosłymi chorymi na schizofrenię i inne zaburzenia psychotyczne ${ }^{23}$. Również w amerykańskim podręczniku Deborah Deutsch Smith niewiele uwagi poświęca osobom chorym na zespoły psychotyczne ${ }^{24}$.

Tymczasem uregulowania prawne wymuszają powstawanie środowiskowych domów samopomocy, służących realizacji idei psychiatrii środowiskowej. $\mathrm{W}$ takich domach celem jest nauczanie chorych na schizofrenię czynności użytecznych w życiu codziennym $\mathrm{w}$ naturalnym środowisku człowieka, dalekim od szpitala psychiatrycznego, który ma charakter instytucji totalnej25. Chorych uczy się racjonalnego wydawania pieniędzy, wypełniania kwitów, płacenia rachunków, robienia zakupów, planowania wydatków, gotowania posiłków, dbania o higienę osobistą. Prowadzi się też treningi umiejętności społecznych oraz treningi komunikacyjne. Propaguje się czytelnictwo czasopism i książek. Chorym zapewnia się rozrywkę i zaspokaja się ich podstawowe potrzeby związane $\mathrm{z}$ tworzeniem więzi z innymi ludźmi oraz uczestnictwem w życiu społecznym. W placówkach zawsze są dostępni psycholog i pracownik socjalny, a w niektórych ośrodkach także lekarz psychiatra,

ki spotecznej i praktyce pracy socjalnej, red. K. Marzec-Holka, Wydawnictwo Uniwersytetu Kazimierza Wielkiego, Bydgoszcz 2005, s. 46-52.

22 E. Marynowicz-Hetka, Pedagogika spoteczna. Podręcznik akademicki, t. I, Wydawnictwo Naukowe PWN, Warszawa 2006; A. Kotlarska-Michalska, Przyczyny i skutki marginalizacji w Polsce, [w:] Marginalizacja w problematyce pedagogiki społecznej i praktyce pracy socjalnej, ed. cit., s. 69-80.

${ }^{23}$ Pedagogika specjalna, red. W. Dykcik, Wydawnictwo Naukowe UAM, Poznań 2009.

${ }^{24}$ D.D. Smith, Pedagogika specjalna, t. I i II, Wydawnictwo APS, Wydawnictwo Naukowe PWN, Warszawa 2009.

${ }^{25} \mathrm{~K}$. Jankowski, Od psychiatrii biologicznej do humanistycznej... dwadzieścia lat później, Jacek Santorski \& CO Agencja Wydawnicza, Warszawa 1994. 
który często prowadzi zajęcia z zakresu psychoedukacji oraz omawia zasady przyjmowania leków ${ }^{26}$.

W takich domach znajdują zatrudnienie również wykształceni specjaliści z zakresu pedagogiki specjalnej (głównie oligofrenopedagogiki) oraz specjaliści $\mathrm{z}$ dziedziny pracy socjalnej. Zatem potrzeba nauczania o zespołach psychotycznych w toku studiów z zakresu pedagogiki specjalnej wydaje się konieczna z perspektywy potrzeb praktyki społecznej zawodu pedagoga. Niedobrze się stało, że pracę socjalną uczyniono kierunkiem odrębnym od pedagogiki. Praca socjalna $\mathrm{w}$ założeniach ma u podstaw paradygmaty pedagogiki społecznej. Naszym zdaniem, rozdzielenie tych dwóch ważnych dziedzin życia społecznego przyniosło szkodę specjalistom z obu kierunków. Doświadczony pracownik socjalny zajmujący się chorymi na schizofrenię musi mieć kompetencje do nauczania i wychowywania. Podobnie, pedagog specjalny powinien znać podstawowe formy prawne związane $\mathrm{z}$ możliwościami pomocy instrumentalnej dla podopiecznych.

\section{Podsumowanie}

Praca z osobami psychotycznymi stanowi ważny element pracy pedagoga (specjalnego) w obszarze rehabilitacji psychiatrycznej i psychiatrii środowiskowej. Potrzeba społeczna kształcenia profesjonalistów zajmujących się nauczaniem oraz wychowywaniem osób chorych na schizofrenię wymusza uwzględnienie wiedzy z dziedziny psychiatrii w programach studiów z zakresu pedagogiki specjalnej.

\section{Bibliografia}

BaŁAndynowicz A., Probacja. Resocjalizacja $z$ udziałem społeczeństwa, Lex a Wolters Kluwer Polska, Warszawa 2011.

${ }^{26}$ M. Załuska, K. Prot, P. Bronowski, Psychiatria środowiskowa jako środowiskowa opieka nad zdrowiem psychicznym, Instytut Psychiatrii i Neurologii, Warszawa 2007. 
Bose A., Agarwal S.M., Kalmady S.V., VenKatasubramanian G., Cognitive Mapping Deficits in Schizophrenia: A Critical Overview, „Indian Journal Psychological Medicine", 2014 Jan, 36(1).

CHIEN W.T., LEUNG S.F., YeUNG F.K., Wong W.K., Current approaches to treatments for schizophrenia spectrum disorders, part II: psychosocial interventions and patient-focused perspectives in psychiatric care, "Neuropsychiatric Disease and Treatment”, 2013, 9.

GofFMAN E., Piętno. Rozważania o zranionej tożsamości, Gdańskie Wydawnictwo Psychologiczne, Gdańsk 2005.

JANKOWSKI K., Od psychiatrii biologicznej do humanistycznej... dwadzieścia lat później, Jacek Santorski \& CO Agencja Wydawnicza, Warszawa 1994.

KASAI K., Toward an interdisciplinary science of adolescence: insights from schizophrenia research, „Neuroscience Research”, 2013 Feb, 75(2), doi: 10.1016/j.neures.2012. 12.001.

KOTLARSKA-MichalsKa A., Przyczyny i skutki marginalizacji w Polsce, [w:] Marginalizacja w problematyce pedagogiki spotecznej i praktyce pracy socjalnej, red. K. Marzec-Holka, Wydawnictwo Uniwersytetu Kazimierza Wielkiego, Bydgoszcz 2005.

KRAUSE A., Wspótczesne paradygmaty pedagogiki specjalnej, Oficyna Wydawnicza Impuls, Kraków 2010.

LeszTO S., WitusiK A., PIETRAS T., Terapia pedagogiczna dorostych w psychiatrii i w medycynie somatycznej. Ujęcie psychologiczne, biomedyczne i aksjologiczne, Naukowe Wydawnictwo Piotrkowskie, Piotrków Trybunalski 2013.

MARWAHA S., JOHNSON S., Schizophrenia and employment - a review, „Social Psychiatry and Psychiatric Epidemiology", 2004 May, 39(5).

Marynowicz-HetKa E., Pedagogika społeczna. Podręcznik akademicki, t. I, Wydawnictwo Naukowe PWN, Warszawa 2006.

MORSZCZYŃSKA U., Normy w pedagogice. Aksjologiczne i metodologiczne wyznaczniki statusu zdań o powinnościach, Księgarnia Akademicka, Kraków 2009.

Mueser K.T., Deavers F., PenN D.L., CAssisi J.E., Psychosocial treatments for schizophrenia, "Annual Review of Clinical Psychology", 2013, 9, doi: 10.1146/annu rev-clinpsy-050212-185620.

MURRAY-SWANK A.B., DIXON L., Family psychoeducation as an evidence-based practice, "CNS Spectrums", 2004 Dec, 9(12).

NEWTON-HOWES G., WOOD R., Cognitive behavioural therapy and the psychopathology of schizophrenia: systematic review and meta-analysis, „Psychology and Psychotherapy: Theory, Research and Practice", 2013 Jun, 86(2), doi: 10.1111/j.2044-8341. 2011.02048.

PAKYUREK M., YARNAL R., CARTER C., Treatment of psychosis in children and adolescents: a review, "Adolescent Medicine: State of the Art Reviews”, 2013 Aug, 24(2).

Pedagogika specjalna, red. W. Dykcik, Wydawnictwo Naukowe UAM, Poznań 2009.

RAJJI T.K., MirANDA D., MulSANT B.H., Cognition, function and disability in patients with schizophrenia: a review of longitudinal studies, "Canadian Journal of Psychiatry", 2014 Jan, 59(1). 
RECTOR N.A., BECK A.T., Cognitive behavioral therapy for schizophrenia: an empirical review, „The Journal of Nervous and Mental Disease”, 2012 Oct, 200(10), doi: 10.1097/NMD.0b013e31826dd9af.

SIN J., NORMAN I., Psychoeducational interventions for family members of people with schizophrenia: a mixed-method systematic review, "The Journal of Clinical Psychiatry", 2013 Dec, 74(12), doi: 10.4088/JCP.12r08308.

SMITH D.D., Pedagogika specjalna, t. I i II, Wydawnictwo APS, Wydawnictwo Naukowe PWN, Warszawa 2009.

SPECK O., Niepetnosprawni w spoteczeństwie. Podstawy ortopedagogiki, Gdańskie Wydawnictwo Psychologiczne, Gdańsk 2005.

ŚWITAJ P., Doświadczanie piętna i dyskryminacji u pacjentów z rozpoznaniem schizofrenii, Instytut Psychiatrii i Neurologii, Warszawa 2008.

ŚWITAJ P., Piętno choroby psychicznej, „Postępy Psychiatrii i Neurologii”, 2005, 14.

TANSELLA M., THORNICROFT G., LEMPP H., Lessons from community mental health to drive implementation in health care systems for people with long-term conditions, "International Journal of Environmental Research and Public Health", 2014 Apr, 30, 11(5), doi: 10.3390/ijerph110504714.

THORNICROFT G., TANSELLA M., The balanced care model for global mental health, „Psychological Medicine", 2013 Apr, 43(4), doi: 10.1017/S0033291712001420.

THORNICROFT G., TANSELLA M., W stronę lepszej psychiatrycznej opieki zdrowotnej, Instytut Psychiatrii i Neurologii, Warszawa 2010.

TREMPAŁA E., Zagrożenia rozwoju człowieka marginalizacja i wykluczeniem w środowiskach lokalnych a pedagogika społeczna, [w:] Marginalizacja w problematyce pedagogiki społecznej i praktyce pracy socjalnej, red. K. Marzec-Holka, Wydawnictwo Uniwersytetu Kazimierza Wielkiego, Bydgoszcz 2005.

WCIÓRKA J., Psychozy schizofreniczne, [w:] Psychiatria, t. II: Psychiatria kliniczna, red. J. Rybakowski, S. Pużyński, J. Wciórka, Wydawnictwo Medyczne Urban \& Partner, Wrocław 2011.

WCIÓRKa J., Terapia spoteczna, [w:] Psychiatria, t. II: Podstawy psychiatrii, red. A. Bilikiewicz, J. Rybakowski, S. Pużyński, J. Wciórka, Wydawnictwo Medyczne Urban \& Partner, Wrocław 2002.

WIŚNIEWSKI C., Filozofia a wychowanie, Naukowe Wydawnictwo Piotrkowskie, Piotrków Trybunalski 2002.

YAMAGUCHI S., WU S.I., BISWAS M., YATE M., AOKI Y., BARLEY E.A., THORNICROFT G., Effects of short-term interventions to reduce mental health-related stigma in university or college students: a systematic review, „The Journal of Nervous and Mental Disease", 2013 Jun, 201(6), doi: 10.1097/NMD.0b013e31829480df.

ZAŁUSKA M., PROT K., BRONOWSKI P., Psychiatria środowiskowa jako środowiskowa opieka nad zdrowiem psychicznym, Instytut Psychiatrii i Neurologii, Warszawa 2007. 